\title{
Does Tenure and Age Influence Work Environment Perception of Faculty in Business Schools?
}

\author{
Asha Sara Mammen * and Harold Andrew Patrick ${ }^{\dagger}$
}

\section{Abstract}

The right attitudes, belief and spirit of acceptance are the basic essentials to achievement of growth, innovation and sustainability in a constantly changing scenario. One aspect that leads to significant difference in attitudes, belief's and perception are the demographic attributes of employees. Review of literature have shown that there is a negligence of the use of demographics in OB and HRM research leading to a state called black box filled with unreliable, vague and untested theories. Considering the importance and contribution of the Indian educational sector towards the emerging knowledge based and technology driven economy, the core stakeholders which are the faculty need to be in an environment that enables them cater to the development of minds. This paper investigates the influence of demographics which are tenure based and age on the perception held by faculty members towards the dimensions of their psychological work environment. Survey data was collected from a sample of 182 faculty members working in AICTE recognized and state university affiliated business schools in Kerala by administering standardized, valid and reliable tools. One-way ANOVA was used to analyse data. Results show that there was mixed response to perception towards work environment dimensions across

\footnotetext{
* Assistant Professor, T. John Institute of Management \& Science, Bengaluru, India; ashasaramamnen@yahoo.com

† Professor (OB \& HRM), Christ University Institute of Management, Bengaluru, India; haroldpatrick@christuniversity.in
} 
the different tenure based demographics considered such as tenure with current organisation, tenure of teaching experience, tenure of industrial experience, tenure of total work experience and age. The implications, findings and suggestions for future research are detailed.

Keywords: Work environment, Demographics, Tenure, Business schools, Human capital management, Organisational behaviour, Human resource management, Business schools

\section{Introduction}

Most research outside the disciplines of Organisational Behaviour and Human Resource Management utilizes the factors of demographics with the assumption that demographic have an explanation in the research findings (Barak, Cherin \& Berkman, 1998; Cianni \& Romberger, 1995). Lawrence (1997) and Pfeffer (1985) research study states that there is a lack of use of demographics in Organisational Behaviour and Human Resource Management research leading to a state referred as black box. Lawrence (1997) points that despite the critical role that demographics play in research studies, researchers leave it loosely specified and unmeasured creating a black box state of untested and unreliable theories. Recent trends in Organisational Behaviour (OB) and Human Resource Management (HRM) research develop theories, strategies, practices and initiatives taking into consideration specific group of respondents or specific groups in the entire workforce and comparison between groups in a workforce. This requires sensitivity towards the impact of demographics which leads to difference in attitudes, values and behaviour and hence the outcomes (Pfeffer, 1985).

This research is a study considering demographics in the context of business schools. Understanding the importance and contribution of Indian educational sector towards the emerging knowledge based and technology driven economy, the core stakeholders which are the academic faculty need to be in an environment that enables them cater to the development of minds. Business schools are facing strategic challenges as changes occur both in the supply side and demand side of management education. Effective response to these challenges needs to be taken so as to sustain their place in a 
competitive environment. Faculty in business schools are acknowledged as mission critical resource and the perception they hold towards psychological dimensions of work environment plays a role contributing to quality and achievements for a business school (Moratis, van Baalen, Teunter \& Verhaegen, 2005). Previous research studies have shown that perceptions are based on attitudes, beliefs and values held by individuals. Demographic attributes of individual also leads to difference in attitudes, beliefs and values. This forms the basis on which the current study is done which is to find out if work environment perception differences exist with difference in demographics.

\section{Demographics}

According to Pfeffer (1993) demographics are attributes of those respondents included in the study. These factors or attributes are assumed to have the capacity to explain the research findings. Demographic factors include age, gender, marital status, education, length of service et.al. Demographics are used by governmental as well as non- governmental organisations to learn about the characteristics of the group under study leading to strategy, business model and policy development. Demographic difference exists among most samples respondents considered for study in any research area from Internet users (Li, Kuo, \& Rusell, 1999) to academic faculty (Marschke, Laursen, Nielsen, \& Dunn-Rankin, 2007). Although difference in gender is gradually decreasing, it still exists as depicted in Mediamark Research Inc's national survey (1999).

Gibson and Klein (1970) study considered age and length of service as explanatory demographic variables. The relationship of these two variables with employee satisfaction was asymptotic in nature and varied. The study concluded that employee satisfaction is a function of age and length of service. Further research shows that age has relationship with positive workplace behaviours and outcomes such as higher organisational citizenship behaviour, higher compliance to rules, lower tardiness and absenteeism, counterproductive behaviour and work injuries ( $\mathrm{Ng} \&$ Feldman, 2008). Hellman (1997) states that older employees tend to show lesser turnover intentions or quit their job when they are 
dissatisfied with their job. Younger generations at the workplace are highly valued for their contribution, approach, ideas, and technology savviness. Modern organisations in all sectors have age diversity in the workplace. Age diversity occurs where there are employees of different generations working together in an organisation. Study by Kilduff, Angelmar and Mehra (2000) found that age diverse teams are high performing teams as they are able to come up with varied and vibrant actions and possibilities. The challenge lies in how they perceive the different dimensions of work environment. Focusing on these perception differences and tailoring those aspects of the work environment can lead to higher effectiveness.

Tenure is another demographic variable that plays a predictor role in contributing towards organisational outcomes. More will be the amount of shared understanding and experiences as individuals spent more length of time with the organisation (Wiersema \& Bird, 1993). Increased tenure in an organisation is positively correlated to employee performance and well-being (Finkelstein \& Hambrick, 1990; Wiersema \& Bantel, 1992; Pfeffer, 1993). Research findings of Kushman (1992), Mathieu and Zajac (1990), Meyer and Allen (1997) indicate that organisational tenure is positively correlated to commitment. As length of service increases, an emotional attachment with the organisation is developed making it difficult for the individual to leave (Meyer \& Allen, 1997). Research study by Smerek and Peterson (2007) showed a contrary finding where length of service did not significantly correlate with job satisfaction. As length of service increased, perception towards the seven dimensions of work environment such as superiors, senior management, job opportunities, recognition, advancement, satisfaction with benefits and presence of core value decreased. Positive correlation was shown between length of service and the work itself.

\section{Work Environment}

Organisations have different personalities and so does people. Employees are happier and engaged when they work in an environment that fits them (Stone \& Whelan, 2015). How employees perceive the different dimensions of work environment 
can explain the extent of person to organisation fit. An argument put forward by Kahn (1990) states if employees have a higher perception towards the dimensions of work environment, they are more engaged and invest more in the organisations work. Such a work environment can be considered a healthy work environment. According to Levering and Moskawitz (2004), if employees place higher trust in the management, take pride in what they do and can work as a team with their colleagues, the work environment can be called healthy.

Research works point out that the perception employees hold towards the dimensions of work environment can lead to various outcomes at individual, group and organisational level. Turnipseed and Murkison (2000) study indicated that citizenship behaviour was correlated to higher perception of work environment dimensions such as commitment, peer cohesion, autonomy, physical work environment, task clarity, supervisor support, work stress, and the amount of bureaucracy in the organization. Seister (1984) study on the work environment considering full time community college faculty reported low on cohesion, clarity and innovation. Findings show that work milieu that is predictable and clear leads to educational efficiency. Higher faculty commitment was positively linked to peer cohesion and task orientation and negatively linked to high work demand and control. Capell (1981) study on school teachers found a correlation between faculty cohesion and autonomy exercised by faculty in classrooms on positive performance of students. Brady, Kinnaird, and Friedrich (1980) study showed that those employees whose work environment had higher level of autonomy, support, involvement, cohesion and involvement showed more job satisfaction. Higher work demand led to emotional exhaustion. Turnipseed (1994) research finding show that lesser perception towards work environment variables such as peer cohesion, stress and work pressure, superior support, job and role clarity and autonomy were linked to burnout.

\section{Need and Rationale}

The current management education curriculum requirement involves bringing the various scenarios happening in the business 
world into classroom sessions. This creates a need in the decision makers or authority to recruit and select academicians that have such exposure and experience. Though there are youngsters who are working as full time academicians whose contribution and approach is of value to the organisation and industry. Faculty specialized and expert in various disciplines come together in the workplace and contribute towards the needs of the students and institution. Thus, tenure based demographics that show the amount of time a faculty has engaged in their area of expertise is consider to ascertain if its variation leads to different perception towards how a faculty is psychologically well adjusted to the workplace. Outcomes at individual, group and organisational level need to be optimum and positively oriented. With age and time comes wisdom and experience to deal better with the psychological requirement of the work environment. Work performances of older employees tend to be at a comparable or at a higher level than their younger counterparts. With age comes more commitment and reliability (Bauer \& Erdogan, 2012). This empirical research examines the difference that tenure based demographics and age have on the perception towards work environment. The knowledge derived can be of use by educational decision makers to construct strategies to improve the various individual, group, organisational and environmental outcomes.

\section{Research Question}

Does difference in demographic variables such as tenure with current organisation, tenure of teaching experience, tenure of industrial experience, tenure of total work experience and age lead to difference in how work environment is perceived among business school faculty in Kerala.

\section{Objectives of the Study}

- To find out if perceived difference towards work environment dimensions exists across the different tenure based demographics considered such as tenure with current organisation, tenure of teaching experience, tenure of industrial experience, tenure of total work experience among business school faculty in Kerala. 
- To find out if perceived difference towards work environment dimensions exists across different age groups among business school faculty in Kerala.

\section{Methodology}

\section{Statistical Population and Sample}

The items of the population were faculty working in private unaided self-financing business schools in Kerala which were affiliated to the state universities in Kerala and recognized by All India Council for Technical Education (AICTE). The sampling frame consisted of 61 business schools with a population size of 366. Based on the model by Krejcie and Morgan (1970), the sample size calculated by 182 . The sampling technique involved cluster sampling and simple random sampling. Cluster Sampling was used to divide the state of Kerala into 14 districts which were further labeled as North Kerala, Central Kerala and South Kerala. Simple random sampling was used to select colleges from each district and also faculty from the selected colleges. A response rate of $86.67 \%$ was obtained.

\section{Measurement Tools}

Nine demographic variables namely gender, age, marital status, educational qualification, designation, tenure based demographics namely tenure with current organisation, tenure of teaching experience, tenure of industrial experience and tenure of total work experience.

The construct of work environment was measured using the Work Environment Services Scale (Patrick,2013). The scale consists of nine dimensions and thirty two items such as ethical dimensions (4 items), autonomy (4 items), stress and work pressure (5 items), work practices (2 items), managerial support (3 items), commitment (2 items), role clarity (4 items), social responsiveness ( 2 items) and peer cohesion ( 2 items). The cronbach's alpha obtained was 0.86 . 


\section{Respondents Profile}

Respondents profile was obtained from the nine demographic variables included in the questionnaire. Among the faculty, $42.3 \%$ were male and $57.7 \%$ were female. Age group distribution showed 9.3\% below 25 years, $31.3 \%$ between $26-30$ years, $21.4 \%$ between 31 35 years, $13.2 \%$ in $36-40$ years, $12.7 \%$ in the category $41-50$ years and $12.1 \%$ in the age category above 50 years. Marital status showed $22.5 \%$ to be single, $75.8 \%$ married and $1.6 \%$ of others. Of the participants, $54.9 \%$ had an MBA degree, $23.1 \%$ MPhil, $12.6 \%$ $\mathrm{PhD}$ and $9.3 \%$ included other educational qualification. The designation of the respondents included 3.3\% of Lecturers, $77.5 \%$ of Assistant Professor, 10.4\% Associate Professors and 8.8\% of Professors. Tenure with current organisation showed $48.4 \%$ for $0-2$ years followed by $30.2 \%$ for $2-4$ years, $9.9 \%$ for $4-6$ years, $7.7 \%$ for $6-$ 10 years, $2.7 \%$ between $10-15$ years and $1.1 \%$ between $15-20$ years. The tenure of teaching experience was $9.9 \%$ for $0-2$ years, $23.6 \%$ for $2-4$ years, $14.3 \%$ for $4-6$ years, $22.5 \%$ for $6-10$ years, $13.7 \%$ for $10-15$ years, $4.9 \%$ for $15-20$ years and $11 \%$ for above 20 years. The percentage of faculty with industrial experience between $0-2$ years was $20.3 \%, 2-4$ years was $14.8 \%, 4-6$ years was $12.6 \%$, 6-10 years was $22.7 \%$, between $10-15$ years was $12.1 \%, 15-20$ years was $4.9 \%$ and above 20 years was $12.6 \% .9 .9 \%$ of faculty had tenure of work experience between 2-4 years, $18.7 \%$ between $4-6$ years, $17.6 \%$ between $6-10$ years, $23.1 \%$ for $15-20$ years, $15.4 \%$ each for $15-20$ years and above 20 years.

\section{Results and Discussion}

Hypothesis 1 - There will be no difference in work environment dimensions across tenure based demographics

Hypothesis 1(a) - There will be no difference in work environment dimensions across tenure with current organisation 
Table 1: One-way ANOVA for work environment dimensions across tenure with current organisation

\begin{tabular}{|c|c|c|c|c|c|c|c|c|c|}
\hline 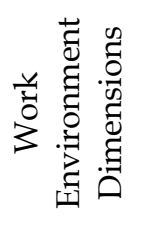 & 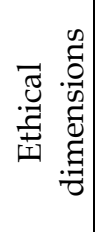 & 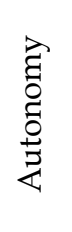 & 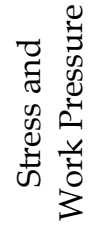 & 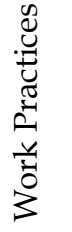 & 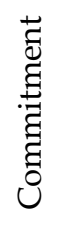 & 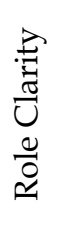 & 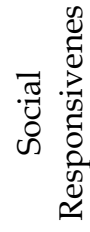 & 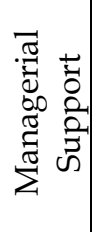 & 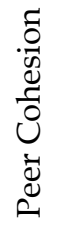 \\
\hline $\mathrm{F}$ & 5.26 & 2.33 & 2.68 & 6.77 & 2.95 & 0.38 & 0.66 & 2.14 & 2.66 \\
\hline Sig. & 0.00 & 0.04 & 0.02 & 0.00 & 0.01 & 0.86 & 0.65 & 0.06 & 0.02 \\
\hline
\end{tabular}

Source : Primary Data

$\mathrm{P}<0.05$

The result obtained from one-way ANOVA showed that there was significant difference in work environment dimension namely ethical dimensions, autonomy, stress and work pressure, work practices, commitment and peer cohesion across the different tenures with current organisation at sig. < 0.05. An ethical dimension (3.57) was perceived highest among faculty with 0-2 years of tenure with the current organisation. Faculty with 4-6 years perceived work practices (3.88) followed by autonomy (3.68). Stress and work pressure (3.80) was highly perceived by faculty with 10-15 years with current organisation. Commitment (5.00) and peer cohesion (5.00) for respondents with 15-20 years in their current organisation measured on a 5-point Likert scale. Length of service or tenure with current organisation can be considered as a life investment a person makes. An employee spends most of his life in the workplace where he plays a role in fulfilling assigned responsibilities, develops acquaintances, works in teams, puts in time and effort, received support and share workload and workspace, participates in non-work related activities which leads to perceiving most of the dimensions of work environment (Becker, 1960).

The null hypothesis is failed to be accepted and the alternate hypothesis: There is a significant difference in perception of work environment dimensions such as ethical dimensions, autonomy, work practices, stress and work pressure, commitment and peer 
cohesion across different tenures with current organisation is supported.

Other dimensions of work environment such as role clarity, social responsiveness and managerial support showed no significant difference with respect to tenure with current organisation. All respondents irrespective of their different tenures with the current organisation share almost same viewpoint regarding the extent of role clarity, social responsiveness and managerial support. Mostly geographical homogeneous workforces have the basic ethical values of a societal culture that is more sentimental and traditional in nature.

The null hypothesis is accepted: There is no significant difference in work environment dimensions such as role clarity, social responsiveness and managerial support across tenure with current organisation.

Hypothesis 1(b) - There will be no difference in work environment dimensions across tenure of teaching experience

Table 2: One-way ANOVA for work environment dimensions across tenure of teaching experience

\begin{tabular}{|c|c|c|c|c|c|c|c|c|c|}
\hline 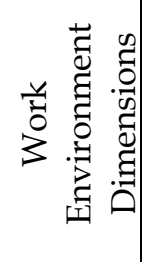 & 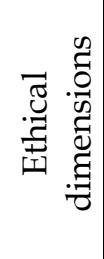 & 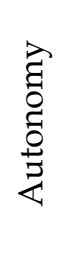 & 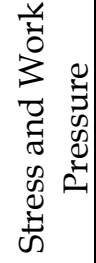 & 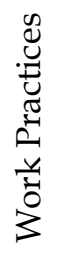 & 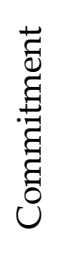 & $\begin{array}{l}\stackrel{\overrightarrow{0}}{\overrightarrow{0}} \\
\vec{U} \\
\frac{0}{0} \\
\stackrel{0}{0}\end{array}$ & 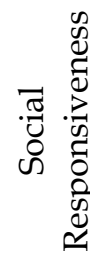 & 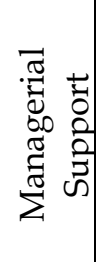 & 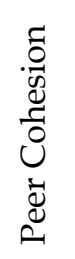 \\
\hline $\mathrm{F}$ & 1.56 & 2.61 & 1.66 & 3.54 & 1.29 & 0.21 & 2.5 & 2.39 & 2.65 \\
\hline Sig. & 0.16 & 0.02 & 0.13 & 0.00 & 0.26 & 0.97 & 0.02 & 0.03 & 0.02 \\
\hline
\end{tabular}

Source : Primary Data

$\mathrm{P}<0.05$

The result obtained from one-way ANOVA showed that there was significant difference in work environment dimension namely autonomy, work practices, social responsiveness, managerial support and peer cohesion across the different tenures of teaching experience at sig. $<0.05$. 
Peer cohesion (4.2) and autonomy (3.68) was perceived highly among faculty with more than 20 years of teaching experience. Faculty with 15-20 years of teaching experience highly perceived the dimension of work practice (3.83). Faculty with teaching experience in the range 6-10 years highly perceived social responsiveness (3.19) and faculty with teaching experience in the range of 0-2 years highly perceived managerial support (3.5) on a 5point Likert scale.

The null hypothesis is failed to be accepted and the alternate hypothesis: There is a significant difference in perception of work environment dimensions such as autonomy, work practices, social responsiveness, managerial support and peer cohesion across the different tenures of teaching experience is supported.

Irrespective of the difference in the teaching experience, faculty showed no difference in perception towards other dimensions of work environment such as ethical dimensions, stress and work pressure, commitment and role clarity.

The null hypothesis is accepted: There is no significant difference in work environment dimensions such as ethical dimensions, stress and work pressure, commitment and role clarity across different tenure of teaching experience.

Hypothesis 1(c) - There will be no difference in work environment dimensions across tenure of industrial experience

Table 3: One-way ANOVA for work environment dimensions across tenure of industrial experience

\begin{tabular}{|c|c|c|c|c|c|c|c|c|c|}
\hline 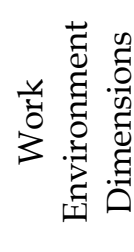 & 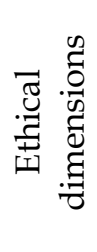 & 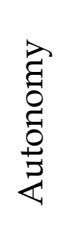 & 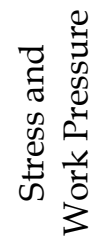 & 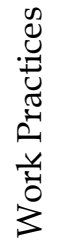 & 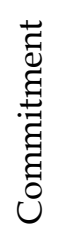 & 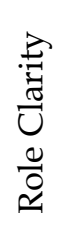 & 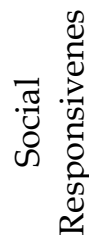 & 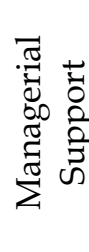 & 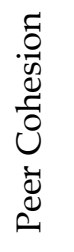 \\
\hline $\mathrm{F}$ & 2.19 & 4.09 & 2.67 & 3.1 & 2.02 & 4.07 & 2.29 & 2.34 & 1.81 \\
\hline Sig. & 0.05 & 0 & 0.02 & 0.01 & 0.07 & 0 & 0.04 & 0.03 & 0.1 \\
\hline
\end{tabular}


The result obtained from one-way ANOVA showed that there was significant difference in work environment dimension namely ethical dimensions, autonomy, stress and work pressure, work practices, managerial support, role clarity and social responsiveness across the different tenures of industrial experience at sig. $<0.05$ on a 5 -point Likert scale.

Peer cohesion (3.89) was perceived highly among faculty with 2-4 years of industrial experience. Faculty with 4-6 years of industrial experience perceived the work environment dimensions such as managerial support (3.88), role clarity (3.81), ethical dimensions (3.69), social responsiveness (3.50). Faculty with teaching experience more than 20 years highly perceived autonomy (3.73) followed by work pressure (3.56).

The null hypothesis is failed to be accepted and the alternate hypothesis: There is a significant difference in perception of work environment dimensions such as ethical dimensions, autonomy, stress and work pressure, work practices, managerial support, role clarity and social responsiveness across the different tenures of industrial experience is supported.

Irrespective of the different tenures of industrial experience, respondents similarly perceived the work environment dimension of commitment and peer cohesion.

The null hypothesis is accepted: There is no significant difference in work environment dimensions such as commitment and peer cohesion across different tenure of industrial experience.

Hypothesis 1(d) - There will be no difference in work environment dimensions across tenure of total work experience 
Table 4: One-way ANOVA for work environment dimensions across tenure of total work experience

\begin{tabular}{|c|c|c|c|c|c|c|c|c|c|}
\hline 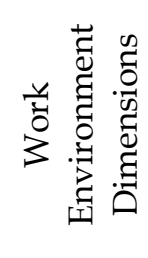 & 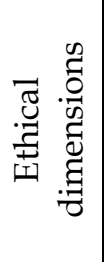 & 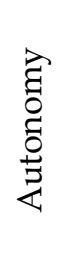 & 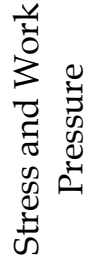 & 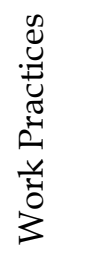 & 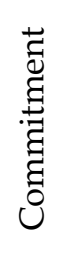 & 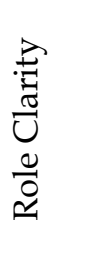 & 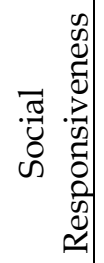 & 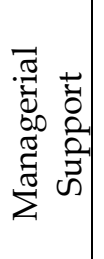 & 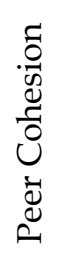 \\
\hline $\mathrm{F}$ & 2.74 & 4.11 & 2.94 & 4.77 & 2.07 & 6.47 & 0.58 & 3.3 & 1.59 \\
\hline Sig. & 0.02 & 0.00 & 0.01 & 0.00 & 0.07 & 0.00 & 0.72 & 0.01 & 0.17 \\
\hline
\end{tabular}

Source : Primary Data

$\mathrm{P}<0.05$

The result obtained from one-way ANOVA showed that there was significant difference in work environment dimension namely ethical dimensions, autonomy, stress and work pressure, work practices, managerial support and role clarity across the different tenure of total work experience at sig. $<0.05$. Faculty with a total experience of 15-20 years perceived the work environment dimensions as follows - work practices (3.89), ethical dimensions (3.77), managerial support (3.68), stress and work pressure (3.55) and autonomy (3.53). Role clarity (3.82) was highly perceived among respondents with 6-10 yrs of tenure. Longer serving employees exert an effort that is beyond what is expected of them towards the running of an organisation thus the order in which the work environment dimensions are perceived (Al-Kahtani, 2004).

The null hypothesis is failed to be accepted and the alternate hypothesis: There is a significant difference in perception of work environment dimensions such as ethical dimensions, autonomy, stress and work pressure, work practices, managerial support and role clarity across the different tenure of total work experience is supported.

Other dimensions of work environment such as commitment, social responsiveness and peer cohesion showed no significant difference with respect to tenure of total work experience. 
The null hypothesis is accepted: There is no significant difference in work environment dimensions such as commitment, social responsiveness and peer cohesion showed no significant difference with respect to tenure of total work experience is supported.

Overall, there was a mixed and varied response to the different work environment dimensions that are perceived by faculty across the tenure based demographics.

Hypothesis 2-There will be no difference in work environment dimensions across age

Table 5 :One-way ANOVA for work environment dimensions across age

\begin{tabular}{|c|c|c|c|c|c|c|c|c|c|}
\hline 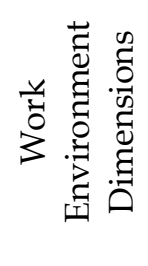 & 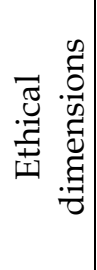 & 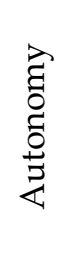 & 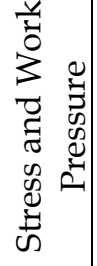 & 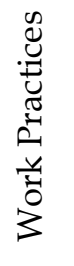 & 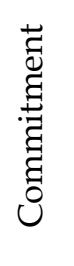 & 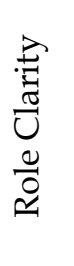 & 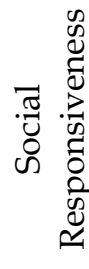 & 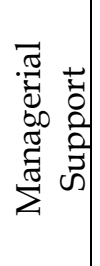 & 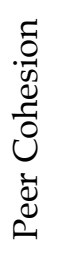 \\
\hline $\mathrm{F}$ & 1.06 & 5.91 & 1.87 & 0.41 & 5.47 & 0.36 & 1.53 & 0.46 & 2.99 \\
\hline Sig & .69 & 0.00 & 0.10 & 0.84 & 0.00 & 0.88 & 0.18 & 0.81 & 0.01 \\
\hline
\end{tabular}

The result obtained from one-way ANOVA showed that there was significant difference in work environment dimension such as autonomy, commitment and peer cohesion across different age groups at sig. $<0.05$. Faculty falling in the age group above 50 years perceived the following work environment dimensions in such order as commitment (4.18), peer cohesion (4.00) and autonomy (3.76) a 5-point Likert scale. This can be attributed to the fact that with age comes higher commitment (Newstrom, 2007). Expectations of older people at the workplace are mostly lowered to a realistic level with better understanding and wisdom to adjust to work situations and peers (Abdulla \& Shaw, 1999). This causes authority to delegate autonomy to them in doing their work.

The null hypothesis is failed to be accepted and the alternate hypothesis: There is a significant difference in perception of work 
environment dimensions such as commitment, peer cohesion and autonomy across different age groups is supported.

Other dimensions of work environment such as ethical dimensions, stress and work pressure, work practices, managerial support, role clarity and social responsiveness showed no significant difference with respect to different age groups.

The null hypothesis is accepted: There is no significant difference in work environment dimensions such as ethical dimensions, stress and work pressure, work practices, managerial support, role clarity and social responsiveness showed no significant difference with respect to different age groups is supported.

The study indicated that with difference in the tenure with current organisation, there is difference in the perception of six of the nine work environment dimensions. Also with difference in the tenure of teaching experience, there is difference in the perception of five out of the nine work environment dimensions. Difference in the tenure of industrial experience led to difference in perceived work environment of seven out of nine dimensions. Six work environment dimensions were perceived differently out of the nine considered dimensions with difference in tenure of total work experience. Different age groups mostly had similar perception towards the nine dimensions of work environment. Only highest age group showed perception towards three out of nine work environment dimensions. This shows that tenure based demographics highly explained difference in perception towards faculty's work environment than age.

Empirical study conducted by Nagamani and Katyayani (2013) on private professional college faculty also found that perceived mixed response towards the work environment dimensions with respect to demographics. Similar empirical studies on faculty demographics and individual work environment factors such as commitment (Iqbal, Kokash \& Al-Oun, 2011), ethical dimensions (Lopez, Rechner \& Olson-Buchanan, 2005), age and work practices (Mehra \& Mital, 2007). Varied perception of work environment dimensions such as autonomy, work practices, peer cohesion, role clarity and commitment in nursing tutors with respect to demographics was detected (Finn, 2001). In consistent with the 
results of this study were the findings of Iqbal (2010), Salami (2008) and Newstrom (2007) empirical work related to tenure based demographics on perceived work environment dimensions.

Putting together all the dimensions of work environment that influenced perception towards work environment by tenure based demographics and age; we find that it includes the entire nine dimensions that were considered for the study.

\section{Implications and Suggestions}

Human behaviour is an outcome of not just the individual alone but also of the situation one is in (Kristof, 1996). The concept of person-environment fit contributes to explain human behavioural outcomes at the workplace. Research finding by Lauver and Kristof-Brown (2001) indicate that employee attitude and values describes the extent of person-environment fit. Perception towards the dimensions of work environment is explained in terms of the concept of person to environment fit. Management pioneers have given much attention to this concept as it is a link between the characteristics of the organisation and the characteristics of the individual. An increasing number of empirical studies have shown show correlation between person to organisation fit and person to job fit with positive work related attitude and outcomes and better perception towards dimensions of the work environment. The concept of person-environment fit can be further classified into person-organisation fit, person-job fit, person-group fit and personperson fit.

According to Kristof (1996), person to organisation fit is the compatibility existing between individual and organisation. This compatibility exits when the two entities share similar characteristics and one entity provides what the other needs. Edward (1991) states that the person to job fit exists when there is a match between the caliber of the individual and the demands of the job. It also is a measure of the extent to which the needs and desires of the individual are met by the job. A person's compatibility with the job is indicated by the person to job fit and compatibility with the organisation's values, goals and mission is indicated by person to organisation fit. 
Researchers and practitioners are finding out what dimensions of both the organisational and individual would influence perception towards person to job fit and person to organisation fit (Lauver \& Kristof-Brown, 2001). Person-environment fit has important implications that lead to both positive and negative outcome at the individual, group and organisational levels. Empirical studies have shown that demographic difference leads to varied attitude, beliefs and values which in turn lead to difference in the perception of the dimensions of work environment. Thus, we can say that demographic attributes in employees lead to significant difference in attitudes, beliefs and values which lead to variation in the person to organisation fit which further lead to difference in the perception towards the dimensions of work environment.

To improve the perception towards work environment, steps taken to improve the person to organisation fit and person to job fit are hence suggested.

Perception towards person to organisation as well as person to job fit can be increased or influenced from the time the individual applied for the job in the organisation. Basically it is the structure of human resource management practices and policies followed by selection and staffing procedures, orientation and training programmes, even evaluation and compensation practices that influence an individual's perception of person to organisation fit. In general, ethical and effective implementation of HRM practices can capture more loyalty from the side of the employees and develop respect towards the values, goals and climate of the organisation. Thus, HRM policy can have the capacity to stimulate an individual's emotional attachment with the organisation with in turn generates better perception towards the work environment dimensions further leading to better organisation outcomes (Takeuchi, Takeuchi \& Toshima ,2004).

Perception towards person to job fit can be improved by investing in employee training and development programmes, skill development programmes, orientation programmes, accurate assessment of the allocated jobs, advice, support and guidance by superiors in doing the allocated job, the right allocated of tasks to employees, appreciation for even the smallest work done, allocating tasks that are interesting and challenging for the 
individual to do, having team member with a the right attitude and interpersonal behaviour. Such practices will cater to facilitate faculty's evaluation towards person to job fit that further leads to the psychologically being willing and motivated to get involved with their jobs (Takeuchi, Takeuchi \& Toshima, 2004).

Gutierrez, Candela and Carver (2012) study findings demonstrated that person-organisation fit positively predicted organisational outcomes such as commitment, productivity, job satisfaction and organisational support among nursing faculty.

\section{Limitations and scope for further study}

The study sample included only private colleges that offer management education. Representativeness of the sample can be further improved. Further study can be done using demographics as a mediating variable and other constructs as independent variable.

\section{Conclusion}

Educational institutions are in an environment of constant change. The latest figures released by All India Council for Technical Education (AICTE) show that of all the states in India- Kerala, Bihar and Jharkhand have only shown growth in management institutions during the period 2014-2015. Management institutions are trying to hold themselves together by improving on its various dimensions both internally and externally. One aspect that they are trying to improve on is the academic faculty. To retain the ones that can further build up and ensure growth is an effort taken by the management and authority. It begins by understanding how faculty feel and perceive their work environment.

Furnham and Schaffer (1984) states that the degree to which employees share the values of their organisation is linked to the degree of satisfaction with that organisation. Social psychologist suggests that people prefer work environments that accepts or match their personality. Hence a good fit between work environment and the individual leads to higher satisfaction. This fit can be referred as person to job fit or person to organisation fit or in 
general, person to environment fit. Higher the perception to the dimensions of person to organisation fit, higher will be the perception towards the different dimensions of work environment as both constructs are influence by attitude, beliefs and values of individuals which are in turn are as a result of the personal characteristics or demographics of the individual.

\section{References}

Abdulla, M. H. A., \& Shaw, J. D. (1999). Personal factors and organizational commitment: Main and interactive effects in the United Arab. Journal of Managerial Issues, 11 (1), 77-93.

Al-Kahtani, M. A (2004). An Assessment of organizational commitment in the Institute of Public Administration in the kingdom of Saudi Arabia: The effects of personal demographics and job-related factors on faculty commitment. Retrieved from ProQuest Digital Dissertations. (305055813)

Bauer, T., \& Erdogan, B. (2012). Introduction to Organisational Behaviour: Managing demographic and cultural diversity. Retrieved from http://2012books.lardbucket.org/pdfs/an-introduction-toorganizational-behavior-v1.1.pdf

Brady, C. A., Kinnaird, K.L., \& Friedrich, W. N. (1980). Job satisfaction and perception of social climate in a mental health facility. Perpectual and motor skills, 51, 559 \& 564. doi: 10.2466/pms.1980.51.2.559

Capell, F. (1981). A study of alternatives in American education: Student outcomes at Alum Rock 1974-76. Santa Monica, CA: Rand Corporation.

Cianni, M., \& Romberger, B. (1995). Perceived racial, ethnic, and gender differences in access to developmental experiences. Group and Organisation Management, 20(4), 440-459.

Finkelstein, S., \& Hambrick, D. C. (1990). Top management-team tenure and organizational outcomes: The moderating of managerial discretion. Administrative Science Quarterly, 35(3), 484.

Finn, C. P. (2001). Autonomy: an important component for nurses' job satisfaction. International Journal of Nursing Studies, 38(3), 349-357. 
Furnham, A., \& Schaeffer, R. (1984). Person-environment fit, job satisfaction and mental health. Journal of Occupational Psychology, 57, 295-307. doi:10.1111/j.2044-8325.1984.tb00170.x

Gibson, J. L., \& Klein, S. M. (1970). Employee attitudes as a function of age and length of service: A reconceptualization. Academy of Management Journal, 13(4), 411-425.

Gutierrez, A. P., Candela, L. L., \& Carver, L. (2012). The structural relationships between organizational commitment, global job satisfaction, developmental experiences, work values, organizational support, and person-organization fit among nursing faculty. Journal of Advanced Nursing, 68(7), 1601-1614.

Hellman, C. M. (1997). Job satisfaction and intent to leave. Journal of Social Psychology, 137, 677-689.

Iqbal, A. (2010). An empirical assessment of demographic factors, organizational ranks and organizational commitment. International Journal of Business and Management, 5(3), 16-27.

Iqbal, A., Kokash, H. A., \& Al-Oun, S. (2011). The impact assessment of demographic factors on faculty commitment in the kingdom of Saudi Arabian universities. Journal of College Teaching \& Learning, 8(2).

Kahn, W. A. (1990). Psychological conditions of personal engagement and disengagement at work. Academy of Management Journal, 33(4), 692-724.

Kilduff, M., Angelmar, R., \& Mehra, A. (2000). Top managementteam diversity and firm performance: Examining the role of cognitions. Organization Science, 11, 21-34.

Krejcie, R V \& Morgan, D. E. (1970). Determining sample size for research activities. Educational and Psychological Measurements. 30, 607-610

Kristof, A. L. (1996). Person-organization fit: An integrative review of its conceptualizations, measurements, and implications. Personnel Psychology, 49, 1-49.

Kushman, J. W. (1992). The organizational dynamics of teacher workplace commitment: A study of urban elementary and middle schools. Educational Administration Quarterly, 28, 5-42.

Lauver, K. J., \& Kristof-Brown, A. (2001). Distinguishing between employees' perceptions of person-job and person-organization fit. Journal of Vocational Behavior, 59, 454-470. 
Lawrence, B. (1997). Perspective - The black box of organizational demography. Organization Science, 8(1), 1-22.

http://pubsonline.informs.org/doi/abs/10.1287/orsc.8.1.1

Levering, R., \& Moskowitz, M. (2004).Creating a great place to work: Why it is important and how it is done. Corrections Today, 66(5), 86-88.

Li, H., Kuo, C., \& Rusell, M. G. (1999). The impact of perceived channel utilities, shopping orientations, and demographics on the consumer's online buying behavior. Journal of Computer-Mediated Communication, 5(2). http://onlinelibrary.wiley.com/ doi / 10.1111 / j.10836101.1999.tb00336.x / full

Lopez, Y. P., Rechner, P. L., \& Olson-Buchanan, J. B. (2005). Shaping ethical perceptions: An empirical assessment of the influence of business education, culture, and demographic factors. Journal of Business Ethics, 60(4), 341-358.

Marschke, R., Laursen, S., Nielsen, J. M., \& Dunn-Rankin, P. (2007). Demographic inertia revisited: An immodest proposal to achieve equitable gender representation among faculty in higher education. The Journal of Higher Education, 78(1), 1-26.

Mathieu, J. E., \& Zajac, D. M., (1990). A review and meta-analysis of the antecedents, correlates and consequences of organizational commitment. Psychological Bulletin, 108(2), 171-194.

Mediamark Research Inc. (1999, May). 64.2 million American adults regularly use the Internet. Retrieved from http:/ / www.mediamark.com/mri/docs/prcss99.htm

Mehra, P., \& Mital, M. (2007). Integrating technology into the teaching-learning transaction: Pedagogical and technological perceptions of management faculty. International Journal of Education and Development using ICT, 3(1).

Meyer, J. P., \& Allen, N. J. (1997). Commitment in the workplace: Theory, research and application. Thousand Oaks, CA: Sage.

Mor Barak, M. E., Cherin, D. A., \& Berkman, S. (1998). Organisational and personal dimensions in diversity climate. Journal of Applied Behavioral Science, 34(1), 82-104.

Moratis, L., Baalen, P. J. V., Teunter, L. H., \& Verhaegen, P. H. A. M. (2005, October 27). Faculty Retention Factors at European Business Schools. How Deans and Faculty Perceptions Differ. From http:// papers.ssrn.com/sol3/papers.cfm?abstract_id=800207\#\# 
Nagamani, G., \& Katyayani, J. (2013). Academician's Perception towards Institutional Culture-Empirical Study of Private Engineering Colleges. International Journal of Management and Social Sciences Research, 2(12).

Newstrom, J. W. (2007). Organizational Behaviour-Human Behaviour at work (12th ed.). New York: McGraw Hill International Edition.

Ng, T. W. H., \& Feldman, D. C. (2008). The relationship of age to ten dimensions of job performance. Journal of Applied Psychology, 93, 392-423.

Lauver. K. J., Kristof-Brown. A. (2001). Distinguishing between Employees' Perceptions of Person-Job and Person-Organization Fit. Journal of Vocational Behavior, 59(3), 454-470.

Pfeffer, J. (1985). Organizational demography: Implications for management. California Management Review, 28(1), 67-81.

Pfeffer, J. (1993). Barriers to the advance of organizational science: paradigm development as a dependent variable. Academy of Management Review, 18(4), 599-620.

Salami, S. O. (2008). Demographic and psychological factors predicting organizational commitment among industrial workers. Anthropologist, 10(1), 31-38.

Seister, S. (1984).The relationship between leader behavior and the work environment. Dissertation Abstracts International, $45,1661 \mathrm{~A}$

Smerek, R. E., \& Peterson, M. (2007). Examining Herzberg's theory: Improving job satisfaction among non-academic employees at a university. Research in Higher Education, 48(2), 229-250.

Stone, Gladys, and Fred Whelan. Interview Questions: Describe Your Ideal Work Environment. Monster Career Advice. 2015. Web. Retrieved from http://career-advice.monster.com/jobinterview/interview-questions/ideal-work-environmentquestion/article.aspx.

Takeuchi, N., Takeuchi, T., \& Toshima, Y. (2004). Psychological Processes of Employees' Perceptions of HRM Practices and their Behavioral Outcomes: Assessing a Mediating Role of Person-Environment Fit and Work Commitment in Japanese Organizations. 4th Conference of the Asia Academy of Management Conference. Shanghai, China. Retrieved from http://jgxy. usx. edu. cn/DAOM/027_NorihkioTakeuchi. pdf. 
Economic Times Beureau. (2015, February 4). B-School for Marketing Veterans. Brand Equity. The Economic Times. Retrieved from

http:/ / articles.economictimes.indiatimes.com/2015-02-

04/news/58795974_1_apps-advertising-veterans-yatra-com

Turnipseed, D. L. (1994). An Analysis of the influence of work environment variables and moderators on the burnout syndrome. Journal of Applied Social Psychology, 24, 782-800. doi: 10.1111/j.1559-1816.1994.tb00612.x

Turnipseed, D., \& Murkison, G. (2000). Good soldiers and their syndrome: Organizational citizenship behavior and the work environment. North American Journal of Psychology, 2(2), 281-303.

Wiersema, M. F., \& Bantel, K. A. (1992). Top management team demography and corporate strategic change. Academy of Management Journal, 35(1), 91-108.

Wiersema, M.F., \& Bird, A. (1993). Organisational demography in Japanese firms: Group heterogeneity, individual dissimilarity, and top management team turnover. Academy of Management Journal, 5(5), 49-60. 